\title{
Çocukluk Çağı Alerjik Hastalıklarında Tamamlayıcı ve Alternatif Tıp Kullanımının Araştırılması
}

\author{
Investigationof the Use of Complementaryand Alternative Medicine in Childhood Allergic Diseases
}

${ }^{1}$ Uludağ Üniversitesi Tip Fakültesi, Çocuk Alerji Bilim Dalı, Bursa, Türkiye

Correspondence: Nihat SAPANUludağ Üniversitesi Tip Fakültesi, Çocuk Alerji Bilim Dalı, Bursa, Türkiye

e-mail:nihatsapan@yahoo.com.tr Received: 26.10 .2020

Accepted: 02.12.2020

Online published: 02.12 .2020

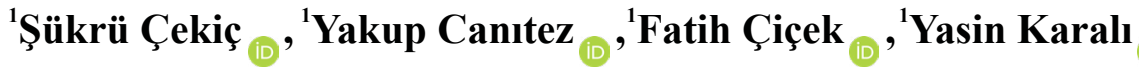 \\ ${ }^{1}$ Zuhal Karalı, , Nihat Sapan
}

\section{Abstract}

Allergic diseases are common chronic diseases in chilhood. Treatmentfailure, longtreatment periods, fear from the side effects of drugsandthinking CAM methods more harmlesslead peopleto alternative treatment methods. Inthis study, ouraim is toinvestigatetheuseandreasons of comple mentaryand alternative medicine (CAM) methods in ourpatientswhoappliedtoouroutpatientclinicandwerefollowedupforvariousallergic diseases. The study was conducted between August 2019 andAugust 2020. Patients with anyallergic diseases were included in the study. A question naire consisting of a total of 24 questions about their primary diseases and CAM was applied to the participants. One hundred two cases were included in the study. The femalemaleratio of the cases was 0.7 and the meanagewas $10.4 \pm 5.6$ years. The rate of using comple mentaryand alternative medicine was found to be $34.6 \%(\mathrm{n}=36)$. Whilethemostfrequentdisease in thestudygroupwasallergicrhinitis $(n=64,62.7 \%)$, the most commondisease in which CAM methods were usedwasfoodallergies $(\mathrm{n}=11,40.7 \%)$. Her baltreatments were commonlyused in CAM method $(\mathrm{n}=19,31.1 \%)$. Themeanage of the mother and father was found to be lower in patientsusing CAM comparedtothose who did not. Inaddition, the rate of using CAM washigher in patients whoappliedtoprivatepracticeorclinicandreceivedin formation from the families of other patients and the people around them. Patients maytendtoseek alternative methods because of the factthat patients' expectationsare not fulfilled in the treatment of chronic diseases. Despitet headvances in modern treatment methods, it has beenobservedthattheuse of CAM in individualswithallergicdiseases is significant, and thetendency of the parentstouse CAM increases as theage of the parentsgets younger.

Keywords: Complementaryandalternativemedicine, asthma, allergicrhinitis, herbaltherapy, apitherapy 


\section{Giriş}

Alerjik hastalıklar hafif yakınmalardan hayatı tehdit eden reaksiyonlara kadar geniş spektrumda belirtilere neden olabilen ve genel olarak s1k görülen kronik hastalıklardır (1). Astım, alerjik rinit, atopik dermatit, ürtiker, anafilaksi, besin alerjileri, ilaç alerjileri ve venom alerjileri yaygın görülen alerjik hastalıklara örnek olarak verilebilir. Birçok kronik hastalıkta olduğu gibi alerjik hastalıklarda da mutlak kür sağlayıcı tedavi bulunmamaktadır. Uzun süreli tedavi gereksinimleri, tedavide aksamalara, tedavi uyumunun azalmasına ve alternatif yöntem arayışına neden olabilmektedir (2).

Tamamlayıcı ve alternatif tıp (TAT) terimi iki ana başlıktan oluşmaktadır. Alternatif tıp, günümüz modern tıbbı tarafindan kabul görmeyen ve modern tıbbi tedavilerin yerine kullanılan uygulamaları, tamamlayıcı tıp ise modern tıbbi tedavilere ek olarak uygulanan tedavi yöntemlerini temsil eder (3). Kronik hastalıklar başta olmak üzere çeşitli hastalıklarda; tedavi başarısızlığı, uzun süreli tedaviler, ilaçlara bağlı yan etkilerin yarattığı endişe ve TAT yöntemlerinin daha zararsız olduğunun düşünülmesi, hastaları TAT kullanımına yönelten nedenler olarak görülmektedir (4-11). Bununla birlikte TAT kronik hastalığı olmayan çocuklarda da yaygın olarak kullanılmaktadır (12). Astımlı çocuklarda TAT kullanımı \%90'lara varan sıklıkta bildirilmektedir (13).

Tamamlayıcı ve alternatif tıp yöntemleri coğrafik bölgelere ve kültürlere göre çeşitlilik arz etmektedir. Alerjik hastalıklarda TAT kullanımının yaygın olarak kullanıldığını gösteren çok sayıda çalışma vardır (14-16). Ancak hastaların TAT kullanımını etkileyen faktörlerle ilgili veriler yetersizdir. Bu çalışmada hastalarımızda TAT kullanma sıklığının, kullanılan yöntemlerin ve TAT kullanımını etkileyen faktörlerin araştırılması amaçlanmıştır.

\section{Gereç ve Yöntem}

Çalışma Uludağ Üniversitesi Tıp Fakültesi Çocuk Alerji Polikliniğinde Ağustos 2019 ve Ağustos 2020 tarihleri arasında yapıldı. Rutin kontrolleri için başvuran ve doktor tanılı herhangi bir alerjik hastalığı olan hastalar çalışmaya alındı. Hastalara tarafımızca hazırlanan 24 sorudan oluşan anket soruları yöneltildi. Anket soruları; hastanın yaşadığı yerin, fiziksel koşullarının, gelir düzeyinin ve eğitim seviyesinin, hastalıklarına ve tedavilerine genel bakışlarının ve TAT kullanımları ile ilgili soruların olduğu toplam 24 sorudan oluşturuldu. Çalışma için Uludağ Üniversitesi Tıbbi Araştırmalar Etik Kurulundan 2019-14/33 numaralı etik onay alındı.

\section{Istatistik}

Nicel değişkenler ortalama \pm standart sapma veya ortanca (en az, en çok) değerleriyle verilmiştir. Nicel verilerin homojen dağılıp dağılmamasına göre karşılaştırılmalarında bağımsız örneklem T testi veya Mann-Whitney $\mathrm{U}$ testi kullanılmıştır. Kategorik değişkenler ise n (\%) olarak ifade edilmiş bağımsız değişkenler için Pearson Ki-kare testi veya Fisherexact test kullanılmıştır. Analizler SPSS (IBM Corp. Released 2015. IBM SPSS Statisticsfor Windows, Version 23.0. Armonk, NY: IBM Corp.) programında yapılmış olup, istatistiksel analizlerde tip I hata düzeyi $\alpha=0.05$ kabul edilmiştir.

\section{Sonuçlar}

Çalışmaya 102 olgu alındı. Olguların kız erkek oranı 42/60 ve ortalama yaşları 10,4 \pm 5,6 yıl idi. Çalışmaya katılan hastalardaki en sık alerjik hastalık alerjik rinitti $(n=64, \% 62,7)$. Olguların tanılarının sıklıklarına göre dağılımı ve genel özellikleri tablo 1'de verilmiştir.

Çalışmamızda 36 hastanın $(\% 34,6)$ bir veya daha fazla TAT yöntemini kullandığı belirlenmiştir. Kullanılan yöntemlerin sıklıklarına göre dağılımı tablo 2'de gösterilmiştir. 
Tablo 1. Alerjik hastalıkların genel popülasyonda ve TAT (yöntemi )kullananlar içinde dağılımı

\begin{tabular}{lll}
\hline Tanılar & Genel dağılım (n=102) (\%) & $\begin{array}{l}\text { TAT kullananlar içinde? } \\
\text { dağılım (n=36)* (\%) }\end{array}$ \\
\hline Alerjik rinit & $64(62,7)$ & $26(40,6)$ \\
\hline Astım & $45(44,1)$ & $17(37,8)$ \\
Besin alerjisi & $27(26,5)$ & $11(40,7)$ \\
\hline Atopik dermatit & $15(14,7)$ & $5(33,3)$ \\
\hline Akut ürtiker & $13(12,7)$ & $2(15,4)$ \\
Anafilaksi & $5(4,9)$ & $1(20)$ \\
*Bazı hastaların birden fazla tanısı vardır. & \\
TAT: Tamamlayıcı ve alternatif tıp & \\
\hline
\end{tabular}

Tabl 2. Uygulanan TAT yöntemleri ve sıklıkları

\begin{tabular}{|ll}
\hline Kullanılan yöntemler & $\mathbf{n}(\mathbf{( \% )}$ \\
\hline Bitkisel tedavi & $19(31,1)$ \\
\hline Apiterapi & $15(24,6)$ \\
\hline Dua etmek & $13(21,3)$ \\
\hline Vitamin/ mineral desteği & $4(6,6)$ \\
\hline Hacamat uygulaması & $3(4,9)$ \\
\hline Kupa uygulaması & $1(1,6)$ \\
\hline Biyorezonans & $1(1,6)$ \\
\hline Yöntem belirtmeyenler & $5(8,2)$ \\
\hline Toplam & $61(100,0)$ \\
\hline *Bazı hastalar birden fazla TAT yöntemi kullanmıştır. \\
TAT: Tamamlayıcı ve alternatif tıp \\
\hline
\end{tabular}

Tamamlayıcı ve alternatif tıp kullanan hastaların ortanca yaşları $(7,5$ yıl $(1,2-18,7))$ ve izlem süreleri (48 ay (3-180) ile kullanmayanların ortanca yaş $(12,2$ yıl $(0,7-$ 19,5) ve izlem süreleri (36 ay (1 -132)) arasında anlamlı fark yoktu $(\mathrm{p}=0,065$ ve $\mathrm{p}=0,348)$.

Tamamlayıcı ve alternatif tıp kullanan ve kullanmayan hastalar karşılaştırıldığında; TAT kullanan hastaların anne ve baba yaşları $(34,9 \pm 5,1$ ve $38 \pm 6$ yıl) kullanmayanlara göre $(38 \pm 6,2$ ve $42,6 \pm 6,9$ yıl $)$ anlamlı olarak düşüktü ( $p=0,013$ ve $p=0,002)$. Erkek çocuklarda $(n=27$, $\% 45)$ kız çocuklara göre $(n=9, \% 21,4)$ TAT kullanımı daha yaygındı $(\mathrm{p}=0,02)$. Ayrıca hastalığı ile ilgili başka hastaların ailelerinden $(n=10, \% 55,6)$, çevresindeki diğer insanlardan bilgi aldığını ifade eden $(n=14$, $\% 66,7$ ) ve özel muayenehane veya kliniğe başvuran hastalarda TAT kullanımı $(\mathrm{n}=17, \% .54,8)$, diğerlerine göre (sırasiyla $n=8, \% 44,4 ; n=7, \% 33,3 ; n=14, \% .45,2$ ) anlamlı olarak yüksekti (sırasılyla $\mathrm{p}=0,047, \mathrm{p}=0,001 \mathrm{ve}$ $\mathrm{p}=0,006)$. Tamamlayıcı ve alternatif tıp kullanan ve kullanmayan hastaların karşılaştırılmaları tablo 3'de gösterilmiştir.

Tamamlayıcı ve alternatif tıp kullanan hastalar bu yöntemlere en sik ilk tanı sirasında $(n=14, \% 38,9)$ ve en sik zararsız olduklarını düşündükleri için başvurmuşlardı $(\mathrm{n}=11, \% 30,6)$. Hastaların TAT yöntemlerine başlangıç zamanları ve nedenleri Tablo 4'de gösterilmiştir. Tamamlayıcı ve alternatif tıp yönteminden fayda görüp görmediklerinin sorulduğu soruya 33 hasta yanıt vermiştir. Bu hastaların \%70'i ( $\mathrm{n}=23)$ k1smen veya belirgin fayda gördüklerini ifade ederken \%30'u fayda görmediğini ifade etmiştir. Tamamlayıcı ve alternatif tıp kullanan hastalardan hiçbiri yan etki tarif etmemiştir. 
Tablo 3. Tamamlayıcı ve alternatif tıp uygulayan ve uygulamayan hastaların özelliklerinin karşılaştırılması

\begin{tabular}{|c|c|c|c|}
\hline & $\begin{array}{l}\text { TAT kullananlar } \\
\text { n (\%) }\end{array}$ & $\begin{array}{l}\text { TAT kullanmayanlar } \\
\text { n (\%) }\end{array}$ & $\mathbf{p}$ \\
\hline \multicolumn{4}{|l|}{ Cinsiyet } \\
\hline Kadın/Erkek (42/60) & $9 / 27$ & $33 / 33$ & $0,020^{+}$ \\
\hline \multicolumn{4}{|l|}{ Anne eğitim düzeyi } \\
\hline Illkokul & $12(37,5)$ & $20(62,5)$ & $0,830^{+}$ \\
\hline Ortaokul & $2(22,2)$ & $7(77,8)$ & $0,367^{+}$ \\
\hline Lise & $11(34,4)$ & $21(65,6)$ & $0,816^{+}$ \\
\hline Üniversite & $11(40,7)$ & $16(59,3)$ & $0,548^{+}$ \\
\hline Çalıșan anneler & $12(33,3)$ & $24(66,7)$ & $0,836^{+}$ \\
\hline \multicolumn{4}{|l|}{ Baba eğitim düzeyi } \\
\hline illkokul & $8(36,4)$ & $14(63,6)$ & $0,827^{+}$ \\
\hline Ortaokul & $4(36,4)$ & $7(63,6)$ & $0,886^{+}$ \\
\hline Lise & $7(24,1)$ & $22(75,9)$ & $0,156^{\dagger}$ \\
\hline Üniversite & $12(42,9)$ & $16(57,1)$ & $0,259^{+}$ \\
\hline \multicolumn{4}{|l|}{ Aylık gelir düzeyi } \\
\hline 2000 TL alti & $4(28,6)$ & $10(71,4)$ & $0,768^{\top}$ \\
\hline $2001-6000 \mathrm{TL}$ arasi & $21(35,6)$ & $38(64,4)$ & $0,484^{+}$ \\
\hline 6000 TL üstü & $6(30)$ & $14(70)$ & $0,749^{+}$ \\
\hline $\begin{array}{l}\text { Birinci derece akrabasında alerji öyküsü } \\
\text { olanlar }\end{array}$ & $9(33,3)$ & $18(66,7)$ & $0,565^{+}$ \\
\hline \multicolumn{4}{|l|}{ Alerjik hastalık } \\
\hline Astım & $17(37,8)$ & $28(62,2)$ & $0,641^{\dagger}$ \\
\hline Alerjik rinit & $26(40,6)$ & $38(59,4)$ & $0,144^{+}$ \\
\hline Atopik dermatit & $5(33,3)$ & $10(66,7)$ & $0,863^{+}$ \\
\hline Besin alerjisi & $11(40,7)$ & $16(59,3)$ & $0,490^{+}$ \\
\hline Anafilaksi & $1(20)$ & $4(80)$ & $0,654^{\pi}$ \\
\hline Akut ürtiker & $2(15,4)$ & $11(84,6)$ & $0,131^{\top}$ \\
\hline \multicolumn{4}{|l|}{ Alerjik hastalığgız hakkında kimlerden bilgi aldıız? } \\
\hline Doktorlardan & $36(36)$ & $64(64)$ & $0,291^{+}$ \\
\hline İnternetten & $21(44,7)$ & $26(55,3)$ & $0,067^{+}$ \\
\hline Gazete / kitaplardan & $5(55,6)$ & $4(44,4)$ & $0,273^{\top}$ \\
\hline Televizyondan & $7(53,8)$ & $6(46,2)$ & $0,212^{\top}$ \\
\hline Başka hasta aileleri & $10(55,6)$ & $8(44,4)$ & $0,047^{+}$ \\
\hline Çevremdeki insanlardan & $14(66,7)$ & $7(33,3)$ & $0,001^{+}$ \\
\hline \multicolumn{4}{|l|}{ Tarafimıza başvurmadan önce baş vurulan merkezler } \\
\hline 1.basamak (aile sağlğı merkezi, dispanser) & $12(52,2)$ & $11(47,8)$ & $0,054^{+}$ \\
\hline 2.basamak (devlet hastanesi, çocuk hastanesi) & $27(42,2)$ & $37(57,8)$ & $0,059^{+}$ \\
\hline $\begin{array}{l}\text { 3.basamak (üniversite hastanesi, eğitim ve } \\
\text { araștırma hastanesi) }\end{array}$ & $15(41,7)$ & $21(58,3)$ & $0,320^{+}$ \\
\hline Özel doktor veya klinik & $17(54,8)$ & $14(45,2)$ & $0,006^{\dagger}$ \\
\hline \multicolumn{4}{|l|}{ Tibbi tedaviye güveniyor musunuz? } \\
\hline Evet & $30(36,6)$ & $52(63,4)$ & \multirow[t]{6}{*}{$0,789^{+}$} \\
\hline Hayir & $1(50)$ & $1(50)$ & \\
\hline Kararsızım & $5(29,4)$ & $12(70,6)$ & \\
\hline Fikrim yok & 0 & $1(100)$ & \\
\hline${ }_{\pi}^{+} \mathrm{Ki}$-kare testi & & & \\
\hline $\begin{array}{l}\text { "Fishere xact test } \\
\text { TAT: Tamamlayıc ve alternatif tip }\end{array}$ & & & \\
\hline
\end{tabular}

\section{Tartışma}

Çeşitli çocukluk çağı akut ve kronik hastalıklarında TAT kullanımı araştırılmıştır (11,12,17-19). Astım başta olmak üzere birçok alerjik hastalık da bu araştırmalara dâhildir (14-16,19-22). Ülkemizde astımda TAT kullanımının sıklığı \%43-49, alerjik rinitte \%14-25, atopik dermatitte \%29,4-46 olarak bildirilmiştir (14-16,19-22). Çalışmamızda genel olarak TAT kullanım sıklığı \%34,6 olarak saptanmıştır. Alerjik hastalıkların alt gruplarına bakıldığında en yüksek TAT kullanma sıklığının besin alerjisi ve alerjik rinit tanılı hastalarda olduğu (\%40,7 ve \%40,6) saptanmıştır.

Tamamlayıcı ve alternatif tıp yöntemleri içinde olan birtakım bitkisel tedavilerin etkinlikleri gösterilmiş olsa da, bunların dozları ve güvenlilikleri ile ilgili belirsizlikler devam etmektedir (7,23-25). Yapılan çalışmaların hemen hepsinde kullanılan TAT yöntemlerinin çeşitliliği ve sıklığı bölgelere ve hastalıklara göre değişmektedir $(6-10,12,14,15,20)$. Orhan ve ark. nın çalışmasında astımlı çocuklarda en sık kullanılan TAT yöntemleri; bıldırcın yumurtası ( $\%$ 79), bitkisel ilaç (\% 31), Türk yabani balı (\% 26), speleoterapi (\% 5) ve arı sütü (\% 5) idi (14). Yine ülkemizden astımlı hastalarda yapılan bir başka çalışmada en sık kullanılan 3 yöntem; bitkisel ilaç (\% 29,7), bildırcın yumurtası (\% 16,1) ve Türk balı (\% 14,4) idi (15). Astımlı çocuklarda TAT kullanımı ile ilgili daha yakın zamanda yapılan bir çalışmada ise en sık kullanılan yöntemler; pekmez içmek (\% 72.5), bitki ve baharat kullanımı (\%70) ve bal kullanımıydı (\%37) (22). Soyer ve ark. tarafından yapılan atopikdermatitli çocuklarda yaptıkları çalışmada ise en sık kullanılan TAT yöntem dua etmekti (16). Alerjik rinitli çocuklarda yapılan bir çalışmada ise kullanılan en sık TAT yönteminin bitkisel tedaviler olduğu saptanmıştır (21). 
Tablo 4. Tamamlayıcı ve alternatif tıp (yöntemlerine ) başlama zamanları ve nedenleri

\begin{tabular}{|ll|}
\hline TAT yöntemine başlama zamanı & n (\%) \\
\hline IIlk tanı sırasında & $14(38,9)$ \\
\hline Hastalık kontrol altında iken & $9(25)$ \\
\hline Tıbbi tedaviye yanıt alınamadı̆ı̆nda & $11(30,6)$ \\
\hline Tıbbi tedavi bittikten sonra & $2(5,6)$ \\
\hline TAT yöntemi kullanma nedenleri* & $10(27,8)$ \\
\hline Tıbbi tedaviden fayda görmeme & $1(2,8)$ \\
\hline TAT yöntemlerinin dahaiyi olduğuna inanma & $11(30,6)$ \\
\hline TAT yöntemlerinin daha zararsız olduğunu düșünme & $5(13,9)$ \\
\hline Yakın çevredeki insanların baskısı & $5(13,9)$ \\
\hline Vicdanen rahat hissetme & $7(19,4)$ \\
\hline Diğer & \\
\hline TAT: Tamamlayıcı ve alternatif tıp & \\
*Bazı hastalar birden fazla seçenek işaretlemiștir. &
\end{tabular}

Slader ve ark. tarafindan yapılan derlemede TAT kullanımıyla ilgili farklı ülkelerden birçok erişkin ve çocuk çalışması incelenmiş ve sıklıkla kullanılan yöntemlerin bitkisel tedavi, nefes alma teknikleri, homeopati ve akupunktur olduğu bildirilmiştir (26). Çalışmamızda ise en sık kullanılan TAT yönteminin bitkisel tedaviler olduğu $(\% 31,1)$ ve bunu apiterapinin $(\% 24,6)$ takip ettiği saptanmiştır.

Astımda TAT kullanımının araştırıldığı bir çalışmada; düşük astım kontrolünün (yüksek astım nöbetleri, acil vizitleri, hastaneye yatıs oranları) TAT kullanımının en önemli belirleyicisi olduğu tespit edilmiștir (15). Atopikdermatitli hastalarda ise en önemli etken tedavi başarıs1zlığı olmuştur (16). Orhan ve ark. tarafindan yapılan çalışmada ise ilaç skorları ve acil başvuru oranları daha yüksek hastalarda TAT kullanımının anlamlı olarak yüksek olduğu saptanmıştır (14). Aynı çalışmada anne eğitim düzeyleri benzerken, baba eğitim düzeyi TAT kullananlarda daha düşük saptanmıștır (14). Birçok çalışmada ise TAT kullanımını etkileyen anlamlı faktör saptanmamıştır $(21,22,27,28)$. Çalışmamızda TAT kullanımını etkileyen faktörler araştırıldığında, sosyoekonomik özelliklerin TAT kullanan ve kullanmayan hastalar arasında benzer olduğu, anne ve babanın eğitim düzeyinin ve ailenin gelir düzeyi düşüklü $\neg$ ğünün TAT kullanım sıklığını artırmadığı saptandi. Ancak daha genç ebeveynlere sahip çocuklarda, hastalığı hakkında çevresindeki insanlardan bilgi alanlarda ve özel muayenehane veya kliniğe başvuran hastalarda TAT kullanımının daha sık olduğu tespit edilmiştir. Bu durumun son yıllarda TAT kullanımının tekrar popüler olması ve genç anne babaların internet ve sosyal medya aracılığıyla TAT kullanımına özendirici bilgilere daha fazla maruz kalmaları ile ilișkili olabileceğini düşünüyoruz. Özel muayenehane veya kliniklere başvuran hastalarda TAT'ın sık kullanılmasının nedeninin; ebeveynlerin TAT kullanma eğiliminin yüksek olması veya özel muayenehanelerde veya kliniklerde TAT kullanımının daha çok önerilmesiyle ilgili olup olmadığı net değildir.

Medikal tedaviden fayda görmeme, ilaç yan etkilerinden korkma ve TAT yöntemlerinin daha zararsız olduğunu düşünme hastaları TAT kullanımına yönelten yaygın nedenler olarak bildirilmektedir (5). Çalışmamızda TAT kullanımının nedeni sorulduğunda en çok işaretlenen yanıt; TAT yöntemlerinin daha zararsız olduğunu düşünmeleri olmuştur.

Çalışmamızda TAT kullanan hastaların \%70'i belli düzeylerde fayda gördüğünü ifade etmiştir. Tamamlayıcı ve alternatif tıp tedavisi uygulayan hastaların tedaviden fayda görme oranları çalışmalar arasında farklılık göstermektedir. Bir çalışmada astımlı çocuklarda TAT tedavisi kullanan ebeveynlerin $\% 75,5$ 'i çeșitli düzeyde fayda gördüğünü ifade ederken bașka bir çalışmada bu oran $\% 14,5$ olarak bildirilmiştir $(15,22)$.

Tamamlayıcı ve alternatif tıp yöntemlerinin daha az yan etkisi olduğu düşünülse de birçok çalışmada çeşitli yan etkilerin oluştuğu bildirilmiştir $(12,19,29)$. Çalışmamızda ise TAT kullanan hastalar herhangi bir yan etki bildirmemiștir

Çalışmamızda TAT yöntemleri kullanan ve kullanmayan hastalar arasında tıbbi tedaviye güven noktasında anlamlı fark saptanmamıştır. Bu durum hastaların TAT yöntemlerini daha çok tamamlayıcı tedavi amacıyla kullandıklarını düşündürmüștür. Ancak katılımcıların hastaneye başvuran hastalardan oluşması nedeniyle bu sonucun toplumdaki gerçek durumu yansıtamayabileceğini düşünüyoruz.

\section{Sonuç}

Çalışmamızda çocuk alerji polikliniğimize başvuran ve çeşitli alerjik hastalıklara sahip olan hastalarda TAT yöntemleri kullanımı önemli olmakla birlikte önceki yıllarda yapılan çalışmalara benzer sıklıktadır. Genç ebeveyn yaşı, sağlık konularında çevresindeki insanlardan fikir alma ve özel muayenehane veya kliniklere başvuru, TAT kullanımını artıran faktörler olarak öne çıkmaktadır. 
1. Bacharier LB, Boner A, Carlsen KH, et al; EuropeanPediatricAsthmaGroup: Diagnosisandtreatment of asthma in childhood: A Practallconsensusreport. Allergy 2008; 63: 5-34.

2. Jin J, Sklar GE, Min Sen Oh V, et al .Factorsaffectingtherapeuticcompliance: A reviewfromthepatient'sperspective. TherClin Risk Manag. 2008;4:269-86.

3. Definingand describing comple mentaryand alternative medicine. Panel on definitionand description, CAM Research Methodology Conference, April 1995. AlternTherand Health Med 1997; 3: 49-57.

4. Kemper KJ. Complementaryandalternativemedicineforchildren: Does it work? ArchDis Child 2001; 84: 6-9. 5. Karayağız Muslu G, Öztürk C. Tamamlayıcı ve alternatif tedaviler ve çocuklarda kullanımı. Çocuk Sağlığı ve Hastalıkları Dergisi 2008; 51: 62-7.

6. Aguiar Júnior Ndos R, Costa IM. Theuse of alternative or comple mentary medicine for children with atopicdermatitis. An BrasDermatol2011;86:167-8.

7. Boneberger S, Rupec RA, Ruzicka T. Complementarytherapyforatopicdermatitisandotherallergic skin diseases: factsandcontroversies. ClinDermatol 2010;28:57-61.

8. Hughes R, Ward D, Tobin AM, et al. Theuse of alternativemedicine in pediatricpatientswithatopicdermatitis. Pediatr Dermatol 2007;24:118-20.

9. Johnston GA, Bilbao RM, Graham-Brown RA. Theuse of complementarymedicine in childrenwithatopicdermatitis in secondarycare in Leicester. Br J Dermatol 2003;149:566-71.

10. Simpson EL, Basco M, Hanifin J. A cross-sectionalsurvey of complementaryandalternativemedicineuse in patientswithatopicdermatitis. J ContactDermat 2003; 14:144-7.

11. Jean D, Cyr C. Use of complementaryandalternativemedicine in a general pediatricclinic.Pediatrics 2007;120:e138-41.

12. Tuncel $T$, Şen V, Kelekçi $S$, et al. Kronik hastalığ olmayan çocuklarda tamamlayıcı ve alternatif tıp kullanımı. Türk PedArş 2014; 49: 148-53.

13. Braganza S, Ozuah PO, Sharif I. Theuse of complementarytherapies in inner-cityasthmaticchildren. J Asthma 2003; 40: 823-7.

14. Orhan F, Sekerel BE, Kocabas CN, et al. Complementaryand alternative medicine in children withasthma. Ann Allergy Asthma Immunol 2003; 90: 611-5.

15. Babayigit A, Olmez D, Karaman O, et al. Complementaryandalternativemedicineusein Turkishchildrenwithbronchialasthma. J AlternComplementMed2008;14: 797-9.
16. Soyer OU, Aksoy I, Dallar Y. Theuse of alternativemedicine in childrenwithatopicdermatitis. AllergolImmunopathol (Madr) 2013;41:275-6.

17. Friedman T, Slayton W, Allen S, et al. Use of alternativetherapiesforchildrenwithcancer. Pediatrics1997; 100 : E1.

18. Hagen LE, Schneider R, Stephens D, et al. Use of complementaryand alternative medicine by pediatricrheumatology patients. Arthritis Rheum 2003; 49: 3-6.

19. Tuncel T, Karabel M, Cetemen A, et al. Atopikdermatitli çocuklarda tamamlayıcı ve alternatif tıp kullanımı. Asthma Allergy Immunol 2013;11:178-84.

20. Tuncel T, Cetemen A, Karabel M, et al. Astım ve/veya allerjikrinitli çocuklarda tamamlayıcı ve alternatif tıp uygulamalar1. Asthma Allergy Immunol2014:12;146-51. 21. Sancaklı Ö, Tuncel T, Özdoğru E. Allerjik Rinitli Çocuklarda Tamamlayıcı ve Alternatif Tıp Kullanımının Araştırılması. Asthma Allergy Immunol 2018;16:11-6.

22. Işık $S$, Gül İ, Çetin M. Van İlinde Astım ve/veya AllerjikRinitli Çocuklarda Tamamlayıcı ve Alternatif Tıp Uygulamaları. Türkiye Çocuk HastDerg/Turkish J Pediatr Dis 2018; 2: 131-5.

23. Demirbas D, Aksoy E, Polat S, et al. Endonasalphototherapy in thetreatment of allergicrhinitis. Kulak Burun Bogaz Ihtis Derg 2011;21:198-203.

24. Passalacqua G, Bousquet PJ, Carlsen KH, et al. ARIA update: I--Systematicreview of comple mentaryandalternative medicine forrhinitisandasthma. J AllergyClinImmunol 2006; 117: 1054-62.

25. Kern j, Bielory L. Complementaryandalternativetherapy (CAM) in thetreatment of allergicrhinitis. Curr Allergy AsthmaRep 2014;14:479.

26. Slader CA, Reddel HK, Jenkins CR, et al. Complementaryand alternative medicineuse in asthma: who is usingwhat? Respirology. 2006;11:373-87.

27. Surette S, Vanderjagt L, Vohra S. Surveys of complementaryand alternative medicine usage: A scopingstudy of thepaediatricliterature. ComplementTherMed 2013;21 (Suppl 1):48-53.

28. Torres-Llenza V, Bhogal S, Davis M, Ducharme F. Use of complementaryand alternative medicine in children withasthma. Can Respir J 2010; 17: 183-7.

29. Niggemann B, Grüber C. Side-effects of complementaryand alternative medicine. Allergy.2003;58:707-16. 